\title{
A Comparative Survival Study between Familial and Sporadic Breast Cancer in Iranian Women
}

\section{Amir Shahram Yousefi Kashi ( $\nabla$ shahpoo2002@yahoo.com )}

Cancer Research Center, Faculty of Medicine, Shahid Beheshti University of Medical Sciences, Tehran, IR Iran

\section{Research Article}

Keywords: Survival, Familial breast cancer, Sporadic breast cancer, Iran

Posted Date: September 14th, 2020

DOl: https://doi.org/10.21203/rs.3.rs-72010/v1

License: (c) (i) This work is licensed under a Creative Commons Attribution 4.0 International License. Read Full License 


\section{Abstract}

Background: Breast cancer (BC) is the most common cancer in Iranian women, with 13400 new cases annually. A few studies have reported that BC patients with a positive familial history had different prognoses and outcomes.

Objectives: The aim of the present study was to evaluate and compare survival between familial breast cancer (FBC) patients and sporadic breast cancer (SBC) patients in Iranian women.

Methods: In a longitudinal study, 1710 patients with complete medical records from the Cancer Research Center, database were extracted and divided into two groups: the FBC group $(n=311)$ and the SBC group $(n=1399)$. Then, five-year overall survival (OS) and five-year disease -free survival (DFS) for these two groups were evaluated and compared.

Results: The FBC group and SBC group represented $18.22 \% \%$ and $81.8 \%$ of all cases, with mean ages of 44.2 years and 47.7 years, respectively $(p=0.0024)$. There were more advanced stage and positive lymph nodes, higher grade of tumor, more positive lymphovascular invasion and P53 status and higher degrees of negative progesterone receptor status in the FBC group than in the SBC group $(p=0.0200, p=0.0001$, $p=0.0001, p=0.0386, p=0.0182$ and $p=0.0003$, respectively). In the FBC group and SBC group, the five year DFS was $81 \%$ and $86.5 \%$, ( $p=0.0121)$, and the five -year OS was $71.1 \%$ and $76.5 \%$, respectively $(p=0.0401)$.

Conclusions: The findings of this study showed that better five-year OS, five-year DFS and favorable prognostic factors in the SBT group than in the FBC group. The initial results might be helpful as better treatment modalities and careful follow-up in the FBC group.

\section{Introduction}

Breast cancer (BC) is the most common visceral cancer among women around the world. In Iranian women, $\mathrm{BC}$ is the most frequently diagnosed cancer with a second cause of death due to cancer based on the Cancer Registry System (1).

There are 13400 new cases of BC annually, with an incidence rate of 32 in 100000 in Iranian women. In Iran, $B C$ is diagnosed with a mean age of $49 \pm 12$ years and occurs one decade earlier than most developed countries; therefore, we have had major health and treatment problems of burden of this disease (2).

$\mathrm{BC}$ is a heterogeneous cancer, and the outcome and prognosis of the disease depends on the clinical and pathological characteristics, such as age at diagnosis, tumor histology, positive or negative familial history $(\mathrm{FH})$ of $\mathrm{BC}$, marital status, parity status, breast feeding history, benign breast disease, menopausal status, diabetes status, smoking history, alcohol consumption, fatty food regimen, oral contraceptive use, 
high density of breast tissue, stage of tumor, tumor size, nodal status, lymphovascular invasion, P53 status, tumor grade, estrogen receptor (ER) status, progesterone receptor (PR) status and human epidermal receptor 2 (HER2) expression. (3-6).

Based on various studies, $10-30 \%$ of $\mathrm{BC}$ cases had a positive $\mathrm{FH}$ of $\mathrm{BC}$ in their first or second degree relatives, and the clinical and pathological characteristics, outcome and survival of this group are significantly influenced by this risk factor and might differ among familial breast cancer (FBC) and sporadic breast cancer (SBC) patients (7-10).

Some studies have reported that FBC patients had an earlier age, more positive pathologic lymph node involvement, larger tumor size, more advanced stage, negative hormone receptors and unfavorable prognosis than SBC patients. On the other hand, some other studies showed no significant differences between the two groups as these factors (11-14).

There is no study in Iran that compared the clinical, pathological features, prognosis and survival between the FBC group and SBC group.

\section{Objectives}

In this longitudinal study, clinical and pathological characteristics, local recurrence, distant recurrence, 5year disease-free survival (DFS) and 5-year overall survival (OS) in FBC and SBC patients were compared at the Cancer Research Center (CRC) of the Shahid Beheshti University of Medical Sciences (SBUMS) between September 2002 and December 2017.

\section{Materials And Methods}

In this longitudinal study, a consecutive series of patients with BC (3010 patients) from the database at CRC of SBUMS, a referral breast clinic in Tehran, Iran, was extracted.

In the database, between September 2002 and December 2017, only 1710 patients were considered with complete medical records and pathologic diagnosis of primary or metastatic breast cancer, and 1300 breast cancer patients with incomplete medical records were omitted.

The inclusion criteria were as follows: $\mathrm{BC}$ patients with acceptable follow-up after initial diagnosis who had all 23 baseline variables (positive or negative $\mathrm{FH}$ of $\mathrm{BC}$, age at diagnosis, marital status, parity status, breast feeding history, menopausal status, diabetes status, smoking history, fatty food regimen, type of surgery (breast conserving surgery (BCS) or modified radical mastectomy (MRM)), tumor histology, stage of tumor, tumor size, nodal status, lymphovascular invasion, P53 status, tumor grade, ER, PR, HER2 status, local recurrence (if present), distant recurrence (if present), and death (if present)).

The exclusion criteria were BC patients who did not have acceptable follow-up after initial diagnosis and who did not have all 23 baseline variables as mentioned before. 
All included patients were divided into two groups: group A or FBC group (breast cancer patients who had one or more first or second degrees or both within three generations) with 311 patients and group $B$ or SBC group (breast cancer patients without any positive FH of BC with 1399 patients. Then, OS, DFS and prognostic factors for the two groups were evaluated and compared.

After all treatments were over, every BC patient was visited and examined every 3 to 6 months for five years and yearly afterwards. The patients underwent annual mammography. In case of clinical symptoms or signs of any recurrences, patients underwent imaging or biopsy to identify any recurrences.

Until December 2017, all 1710 BC patients were followed. As the time interval between initial diagnosis and local or distant recurrence (if present) was defined as DFS and the time interval between initial diagnosis and death (if present) was defined as OS.

In the act provided by SBUMS, the ethical regulations dictated were approved to review the medical records for the purposes of our study (ethical code: IR.SBMU.MSP.REC.1396.358).

Differences in all 23 variables evaluated and compared by the log-rank test between two groups. A P value $<0.05$ was considered significant. All statistical analyses were performed using IBM SPSS 22.0.

\section{Results}

In this longitudinal study, $1710 \mathrm{BC}$ patients in two groups (FBC group (group A) with 311 patients) and (SBC group (group B) with 1399 patients) were divided. In the FBC group (group A), 121 BC patients (38.9\%) had an affected first-degree relative, 161 breast cancer patients $(51.8 \%)$ had an affected seconddegree relative and $29 \mathrm{BC}$ patients $(9.3 \%)$ had both first- and second-degree relatives (Table 1).

In the FBC group (group A) and SBC group (group B), the mean age was 44.2 years (SD=9.4 years) and 47.7 years $(S D=10.9$ years), respectively. The age of onset seemed to be earlier in group $A$ than in group $B$ $(p=0.0024)$.

In the FBC group, 130 cases (41.8\%) were postmenopausal, and 181 cases (58.2\%) were premenopausal. In the SBC group, 794 cases (56.8\%) were postmenopausal, and 605 cases (43.2\%) were premenopausal. These differences were statistically significant $(R R=1.63,95 \% \mathrm{Cl}=1.33-2.00, p<0.0001)$. Then, the FBC group was more likely to be premenopausal.

Diabetes, smoking and fatty food regimens were seen in $13.8 \%, 6.8 \%$ and $47.9 \%$ of the FBC group and $15 \%, 6.5 \%$ and $48.3 \%$ of the SBC group, respectively, without significant differences ( $R R=0.92,95 \% \mathrm{Cl}=$ $0.68-1.23, p=0.5970, R R=1.03,95 \% \mathrm{Cl}=0.69-1.54, p=0.8727$ and $R R=0.98,95 \% \mathrm{Cl}=0.80-1.20, p=0.9139$ ).

There were 195 patients (62.7\%) with BCS and 116 patients (37.3\%) with MRM in group A, 868 patients (62\%) with BCS, and 531 patients (38\%) with MRM without significant differences ( $\mathrm{RR}=0.98,95 \% \mathrm{Cl}=0.79$ $-1.20, p=0.8291$ ) in group $B$. Table 2 summarizes the baseline clinical and surgical features of 1710 adult patients with $\mathrm{BC}$. 
Insitu carcinoma, invasive ductal carcinoma, invasive lobular carcinoma and other pathology were seen in $0 \%, 93.3 \%, 4.8 \%$ and $1.9 \%$ of the FBC group and $0.6 \%, 90.9 \%, 4.4 \%$ and $4.1 \%$ of the SBC group, respectively, without significant differences $(R R=3.71,95 \% \mathrm{Cl}=0.24-55.47, \mathrm{p}=0.3414, \mathrm{RR}=4.07,95 \% \mathrm{Cl}=$ $0.26-63.04, p=0.3142$ and $R R=2.03,95 \% \mathrm{Cl}=0.12-33.34, p=0.6196)$.

Based on tumor stage, in group A, 51 cases (16.4\%) had stage I, 161 cases (51.8\%) had stage II, 95 cases $(30.5 \%)$ had stage III, and 4 patients $(1.3 \%)$ had stage IV. In group B, 311 cases $(22.2 \%)$ had stage I, 650 cases $(46.5 \%)$ had stage II, 371 cases $(26.5 \%)$ had stage III, and 67 patients $(4.8 \%)$ had stage IV. There were statistically significant differences between groups A and B as stage II and stage III (RR=1.40,95\% $\mathrm{Cl}=1.05-1.88, \mathrm{p}=0.0203$ and $\mathrm{RR}=1.44,95 \% \mathrm{Cl}=1.06-1.97, \mathrm{p}=0.0200)$, but there were no statistically significant differences between groups A and B as stage I and stage IV. The FBC group had more stage II and stage III disease than the SBC group.

$\mathrm{T} 1, \mathrm{~T} 2, \mathrm{~T} 3$ and T4 were seen in $19.1 \%, 47.6 \%, 15.2 \%$ and $18.1 \%$ of the FBC group and $20.4 \%, 47.2 \%, 14.6 \%$ and $17.8 \%$ of the SBC group, respectively, without significant differences $(\mathrm{RR}=1.07,95 \% \mathrm{Cl}=0.81-1.41$, $p=0.6173, R R=1.11,95 \% \mathrm{Cl}=0.79-1.57, p=0.5399$ and $\mathrm{RR}=1.07,95 \% \mathrm{Cl}=0.77-1.49, \mathrm{p}=0.6888$ ).

Node positivity was observed in $72.4 \%$ of the FBC group and $58.9 \%$ of the SBC group, with a statistically significant difference $(\mathrm{RR}=1.57,95 \% \mathrm{Cl}=1.25-1.97, \mathrm{p}=0.0001)$. Then, the $\mathrm{FBC}$ group was more likely to have node positivity.

Positive lymphovascular invasion was seen in group A (46.6\%) and group B (58.9\%), with a statistically significant difference $(\mathrm{RR}=1.24,95 \% \mathrm{Cl}=1.01-1.51, \mathrm{p}=0.0001)$. Group $\mathrm{A}$ had less positive lymphovascular invasion than group $B$.

Positive P53 was observed in $42.1 \%$ of the FBC group and $35.1 \%$ of the SBC group, with a statistically significant difference ( $R R=1.27,95 \% \mathrm{Cl}=1.04-1.56, p=0.0182)$. Then, the $\mathrm{FBC}$ group was more likely to have node positivity. Then, the FBC group had more positive P53 than the SBC group.

Twenty-one patients $(6.7 \%)$ had well-differentiated grades, 154 patients $(49.5 \%)$ had moderately differentiated grades, 136 patients $(43.8 \%)$ had poorly differentiated grades in group A, 168 patients (12.04\%) had well-differentiated grades, 857 patients (39.8\%) had moderately differentiated grades, and 374 patients $(26.7 \%)$ had poorly differentiated grades in group B. There was a statistically significant difference between groups $A$ and $B$ as poorly differentiated grades $(R R=2.40,95 \% \mathrm{Cl}=1.56-3.68$, $p=0.0001)$, but there were no statistically significant differences between groups $A$ and $B$ as welldifferentiated grades and moderately differentiated grades.

Positive ER was seen in group A with $59 \%$ and in group B with $61.3 \%$, without a significant difference statistically $(R R=1.07,95 \% \mathrm{Cl}=0.87-1.31, p=0.4931)$. However, positive $P R$ was observed in group $A$ $(46.7 \%)$ and in group $B(57.8 \%)$, with a statistically significant difference $(R R=1.44,95 \% \mathrm{Cl}=1.18-1.77$, $p=0.0003)$. Then, group A had less PR positivity than group $B$. 
HER2 positivity was observed in $31.9 \%$ of the FBC group and $26.9 \%$ of the SBC group, without a statistically significant difference $(R R=0.82,95 \% \mathrm{Cl}=0.66-1.02, p=0.0798)$. Table 3 summarizes the association between $\mathrm{FH}$ and the pathological characteristics of $\mathrm{BC}$ patients in $\mathrm{CRC}$.

As of December 2017, 10 cases (3.2\%) of local recurrence were shown in the FBC group, and 49 patients (3.5\%) of local recurrence were shown during the five years of follow-up in the SBC group. Thus, the 5year local recurrence-free survival (LRFS) was $96.8 \%$ in the FBC group and $96.5 \%$ in the SBC group. There were no significant local recurrence differences between the FBC group and SBC group $(p=0.8022$, $\mathrm{RR}=0.91,95 \% \mathrm{Cl}=0.47-1.89$ ) (table 4). Patients in the $\mathrm{FBC}$ group did not show more local recurrence than those in the SBC group.

In the FBC group, 49 cases (15.8\%) were diagnosed with distant metastasis during the five years of follow-up, and 140 breast cancer patients $(10.1 \%)$ had distant recurrence in the SBC group. Thus, the 5year distant recurrence-free survival (DRFS) rates were $84.2 \%$ in the FBC group and $89.9 \%$ in the SBC group. This study found a significant difference between the two groups in distant recurrence-free survival $(\mathrm{p}=0.0031, \mathrm{RR}=1.57,95 \% \mathrm{Cl}=1.16-2.12)$ (table 4$)$.

The five-year DFS rates were $81 \%$ and $86.5 \%$ in the FBC and SBC groups, respectively. The study observed a significant difference between the two groups in the five-year DFS $(p=0.0121, R R=1.40,95 \% \mathrm{Cl}=1.07$ 1.83) (Table 4). Patients in the SBC group showed better five-year DFS than those in the FBC group.

In the FBC and SBC groups, the five-year OS rates were $71.1 \%$ and $76.5 \%$, respectively. This study showed a significant difference between the two groups in terms of the five-year OS $(p=0.0401, R R=1.23,95 \%$ $\mathrm{Cl}=1.01-1.50$ ) (table 4). Patients in the SBC group showed better five-year OS than those in the FBC group.

\section{Discussion}

The aim of this study was to show better 5-year DFS and 5-year OS rates in the SBC group than in the FBC group. In the current study, with CRC of SBUMS, clinical and pathological characteristics, local recurrence, distant recurrence, 5-year DFS, and 5-year OS in 1710 breast cancer patients in the FBC and SBC groups were compared, and to the best of our knowledge, this is the greatest series in Iran.

There are 52 epidemiological studies including 58209 women with breast cancer and 101986 without BC that showed a positive $\mathrm{FH}$ of $\mathrm{BC}$ in first or second degrees was an important risk factor for the disease. Based on these studies, $10-30 \%$ of $\mathrm{BC}$ cases had a positive $\mathrm{FH}$ of $\mathrm{BC}$ in their first or second degree relatives. In the current study, $18.2 \%$ of the cases had a positive $\mathrm{FH}$ of $\mathrm{BC}$ in their first- or second-degree relatives, which is consistent with these 52 epidemiological studies (15).

In group $A$ and group $B$, the mean age at diagnosis was 44.2 years and 47.7 years, respectively $(p=0.0024)$. The age of onset seems to be earlier in the FBC group than in the SBC group. This result was consistent with Pharoah et al. and Molino et al who found that breast cancer patients with a positive FH 
were younger than patients with a negative $\mathrm{FH}$ (16-17). For these reasons, women with a positive $\mathrm{FH}$ could benefit more often through mammography and ultrasonography screening since younger age.

Fukutomi et al reported that among patients with a positive $\mathrm{FH}$, premenopausal women were more prevalent than patients with a negative $\mathrm{FH}(18)$. These findings were consistent with this study, which observed that premenopausal patients were more prevalent in the FBC group than in the SBC group $(p<0.0001)$.

$\mathrm{BC}$ is also an environmentally dependent disease, and the influence of some of these environmental risk factors, such as diabetes, smoking and fatty food regimen consumption of this cancer, has been widely studied (19-20). These findings were inconsistent with the current study, which found that there were no statistically significant differences between group $A$ and group $B$ in diabetes, smoking and fatty food regimen consumption $(p=0.5970, p=0.8727$ and $p=0.9139$, respectively).

Gaffield et al showed that oral contraceptive consumption can increase the risk of $B C$ in patients with a positive $\mathrm{FH}$ (21). These findings were inconsistent with this study, which found that there were no statistically significant differences between the FBC group and SBC group in oral contraceptive consumption $(p=0.9525)$.

The study found that there were no significant differences between group $A$ and group $B$ in marital status, parity status, or breast feeding history $(p=0.5642, p=0.8848$ and $p=0.8146$, respectively). However, Olsson et al. showed that the FBC group with a parity history and/or breast feeding had a protective effect compared to the SBC group (22).

Regarding the histological type of tumor, the current study findings did not vary between the two groups. Allen-Brady et al. observed that invasive lobular carcinoma was more common in the FBC group than in the SBC group (23), although this study did not find a statistically significant difference between the two groups in relation to invasive lobular carcinoma (0.3142).

In agreement with Fukutomi et al.'s study (24), this study did not find a significant difference in tumor size between the two groups, but in disagreement with Colditz et al.'s study, which showed a higher proportion of T1 tumors in group A than in group B (25).

Gavrilov et al. reported that patients with a positive history of FBC had a more advanced stage than patients with a negative history of FBC (26). These results were consistent with the current study, which showed that there were more advanced stages in the FBC group than in the SBC group.

In agreement with Marcus et al. and Mohammed et al. (27-28), who showed FBC patients had more tumors with positive lymph node metastasis, positive lymphovascular invasion, positive P53 and higher grade of tumor, this study observed the same results $(p=0.0001, p=0.0386, p=0.0182$ and $p=0.0001$, respectively). 
Molino et al. (29) reported that the FBC group had more ER-positive tumors than the SBC group. These findings were inconsistent with this study, which found that there were no statistically significant differences between the FBC group and SBC group as ER-positive tumors ( $p=0.4931)$ but were similar to the findings of Yamashita et al. (30), who reported that ER-positive tumors were the same in the two groups.

D'Eredita et al (31) found that the FBC group had more PR-negative tumors than the SBC group, which is in agreement with the results of this study $(p=0.0003)$. D'Eredita et al. also indicated that HER2 negativity was the same in these two groups, similar to the results of this study $(p=0.0798)$.

However, Govindan et al. (32) reported that the PR gene polymorphism had an important role in the development of breast cancer.

Russo et al. (33) showed that the 5-year OS was $78.6(95 \% \mathrm{Cl} 70.0-88.0)$ in the FBC group and was lower than that in the SBC group, with a 5-year OS of 79.8 (95\% Cl 77.0-83.0), but they did not differ significantly (log-rank test, $X 2^{2}=0.02, p=1.0$ ). In agreement with this study, which found that the 5 -year OS was 71.1 in the $F B C$ group and $76.5(R R=1.23,95 \% C l=1.01-1.50, p=0.0401)$, but unlike the study by Russo et al., the difference was statistically significant.

Verkooijen et al. (34) found that the risk of BC mortality was the same in BC with or without a positive FH. Their findings were inconsistent with those of the current study, and the FBC group had more BC mortality and less 5 -year OS than the SBC group $(P=0.0401)$. They could not show any comparison, as 5 -year LRFS, 5-year DRFS and 5-year DFS between the two groups, but we showed that 5-year DRFS and 5-year DFS were $84.2 \%$ and $81 \%$ in group $A$ and $89.9 \%$ and $86.5 \%$ in group $B$, respectively $(p=0.0031$ and $\mathrm{p}=0.0121)$.

The limitations of this study included the missing data of some patients' information and the short follow-up period.

\section{Conclusion}

The initial findings of this study showed poorer survival for familial breast cancer patients in Iran. The results of the study indicated that the FBC group was younger and more premenopausal than the SBC group, and they had a more advanced stage, more lymph node involvement, a higher rate of negative PR and a higher grade of tumor than the SBC group. Because of the short follow-up period, this study cannot prove that the SBC group had a better prognosis than the FBC group. A longer follow-up time of the patients to compare 10-year DFS and 10-year OS or even 20-year OS between the two groups is recommended.

\section{Declarations}

Acknowledgments 
This article has been extracted from the database of the Cancer Research Center, Shahid Beheshti University of Medical Sciences, and I would like to thank the staff of that center for their contribution to maintenance of the patient records and data collection without whom carrying out this project would be impossible.

\section{Funding/Support}

The authors received no financial support for the research, authorship, and/or publication of this article.

\section{Conflict of Interest}

There is no conflict of interest to be declared.

\section{References}

1. The Top 10 Causes of Death in 2014, Fact Sheet of WHO Report. World Health Organization, 2008.

2. Goya M. Iranian Annual Cancer Registration Report 2015/2016. Ministry of Health and Medical Education, Health Deputy, Center for Disease Control and Prevention (In Persian). Tehran, Iran, 2007.

3. Benider A, Harif M, Karkouri M et al. Registre des cancers de la region du grand Casablanca (2005.2006.2007). Association Lalla Salma de lutte contre le Cancer 2012.

4. Weigelt B, Reis-Filho JS. Histological and molecular types of breast cancer: is there a 2009; unifying taxonomy? Nat Rev Clin Oncol2009; 6(12): 718-30.

5. Reis-Filho JS, Lakhani SR. Breast cancer special types: why bother? J Pathol 2008; 216: 394

6. Weigelt B, Geyer FC, Reis-Filho JS. Histological types of breast cancer: how special are they? Mol Oncol 2010; 4(3): 192-208.

7. Anderson DE, Badzioch MD. Survival in familial breast cancer patients. Cancer 1986;58:360-5.

8. Wobbes T, van de Wiel MP, van der Sluis RF, et al. The effect of familiality on clinical presentation and survival in mammary carcinoma. Eur J Surg Oncol 1987;13:119-21.

9. Langlands AO, Kerr GR, Bloomer SM. Familial breast cancer. Clin Oncol 1976; 2:41-5.

10. Lynch HT, Albano W, Recerbaren J, et al. Prolonged survival as a component of a hereditary breast and nonpolyposis colon cancer. Med Hypotheses 1981;7:1201-9.

11. Lynch HT, Albano WA, Recabaren JA, et al. Survival in hereditary breast and colon cancer. JAMA 1981; 246:1197. 
12.Albano WA, Recabaren JA, Lynch HT, et al. Natural history of hereditary cancer of the breast and colon. Cancer 1982; 50:360-3.

13. Malone KE, Daling JR, Weiss NS, et al. Family history and survival of young women with invasive breast carcinoma. Cancer 1996;78: 1417-25.

14. Slattery ML, Berry TD, Kerber RA. Is survival among women diagnosed with breast cancer influenced by family history of breast cancer? Epidemiology 1993;4:543-8.

15. Collaborative Group on Hormonal Factors in Breast Cancer. Familial breast cancer: collaborative reanalysis of individual data from 52 epidemiological studies including58209 women with breast cancer and101986 without the disease. Lancet 2001; 358(9291): 1389-99.

16. Pharoah PD, Day NE, Duffy S, Easton DF, Ponder BA. Family history and the risk of breast cancer: A systematic review and metaanalysis. Int J Cancer 1997; 71(5): 800-9.

17. Molino A, Giovannini M, Pedersini R, et al. Correlations between family history and cancer characteristics in 2256 breast cancer patients. Br J Cancer 2004; 91(1): 96-8.

18.Fukutomi T, Akashi-Tanaka S, Nanasawa T, Matsuo K, Shimizu C. Multicentricity and histopathological background features of familial breast cancers stratified by menopausal status. Int J Clin Oncol 2001; 6(2): 80-3.

19. Magnusson C, Colditz G, Rosner B, Bergstrom R, Persson I. Association of family history and other environmental risk factors with breast cancer risk (Sweden). Cancer Causes Control 1998; 9(3): 259-67.

20. Hirose K, Tajima K, Hamajima N, et al. Association of family history and other environmental risk factors with breast cancer risk among Japanese premenopausal and postmenopausal women. Cancer Causes Control 2001; 12(4): 349-58.

21. Gaffield ME, Culwell KR, Ravi A. Oral contraceptives and family history of breast cancer. Contraception 2009; 80(4): 372-80.

22. Olsson $\mathrm{H}$, Bladström A.A cohort study of reproductive factors and family history of breast cancer in southern Sweden. Breast Cancer Res Treat 2002; 76(3): 203-9.

23. Allen-Brady K, Camp NJ, Ward JH, Cannon- Albright LA. Lobular breast cancer: excess familiality observed in the Utah Population Database. Int J Cancer 2005; 117(4): 655-661.

24. Fukutomi T, Kobayashi Y, Nanasawa T, Yamamoto H, Tsuda H. A clinicopathological analysis of breast cancer in patients with a family history. Surg Today1993; 23(10): 849-54.

25. Colditz GA, Willett WC, Hunter DJ, et al. Family history, age, and risk of breast cancer. Prospective data from the Nurses' Health Study. JAMA 1993; 270(3): 338-43. 
26. Gavrilov I, Nacheva M, Tzingilev D. Familial breast cancer. Part II: Relationships with histology, staging, steroid receptors and serum tumor markers. J BUON 2002; 7(1): 61-5.

27. Mohammed SN, Smith $\mathrm{P}$, Hodgson SV, et al. Family history and survival in premenopausal breast cancer. Br J Cancer 2008; 77(12): 2252-6.

28. Marcus JN, Watson P, Page DL, Lynch HT. Pathology and heredity of breast cancer in younger women. J Natl Cancer Inst Monogr1994; (16): 23-34.

29. Molino A, Giovannini M, Pedersini R, et al. Correlations between family history and cancer characteristics in 2256 breast cancer patients. Br J Cancer 2004; 91(1): 96-8.

30. Yamashita H, Iwase H, Toyama T, et al. Estrogen receptor-positive breast cancer in Estrogen receptorpositive breast cancer in Japanese women: trends in incidence, characteristics, and prognosis. Ann Oncol 2011; 22(6): 1318-132.

31. D'Eredita' G, Giardina C, Napoli A, Troilo VL, Fischetti F, Berardi T. Familial and sporadic breast cancers: differences in clinical, histopathological, and immunohistochemical features. Int J Surg Pathol 2011; 19(6): 724-32.

32. Govindan S, Ahmad SN, Vedicherla B, et al. Association of progesterone receptor gene polymorphism (PROGINS) with endometriosis, uterine fibroids and breast cancer. Cancer Biomark 2007; 3(2): 73-8.

33. Russo A, Herd-Smith A, Gestri D, et al. Does family history influence survival in breast cancer cases? Int J Cancer 2002; 99(3): 427-30.

34. Verkooijen HM, Chappuis PO, Rapiti E, et al. Impact of familial risk factors on management and survival of early-onset breast cancer: a population-based study. Br J Cancer 2006; 94: 231-238.

\section{Tables}

Table 1: Distribution of breast cancer patients according to family history in the cancer research center 


\begin{tabular}{|llll|}
\hline Group & Family History & Number & $\%$ \\
\hline Group A, FBC $(\mathbf{n}=\mathbf{3 1 1})$ & Yes & 311 & 18.2 \\
& 1st degree & 121 & 38.9 \\
& 2nd degree & 161 & 51.8 \\
& 1st and 2nd degree & 29 & 9.3 \\
& & & \\
Group B, SBC $(n=1399)$ & No & 1399 & 81.8 \\
& & & \\
\hline
\end{tabular}

${ }^{a}$ FBC: Familial breast cancer, ${ }^{b}$ SBC: Sporadic breast cancer

Table 2. Baseline clinical and surgical features of 1710 adult patients with breast cancer. 


\begin{tabular}{|c|c|c|c|c|}
\hline VARIABLES & $\begin{array}{l}\text { Group A } \\
\operatorname{FBC}^{\mathrm{a}}(\mathrm{n}=311)\end{array}$ & $\begin{array}{l}\text { Group B } \\
\operatorname{SBC}^{b}(n=1399)\end{array}$ & $\mathrm{RR}^{c}\left(95 \% \mathrm{Cl}^{\mathrm{d}}\right)$ & $\mathrm{p}$ value \\
\hline Mean age at diagnosis (years) & $44.2(\mathrm{SD}=9.4)$ & $47.7(S D=10.9)$ & - & 0.0024 \\
\hline \multicolumn{5}{|l|}{ Marital status, n (\%) } \\
\hline Married & $295(94.9)$ & $1315(94)$ & 1 & \\
\hline Single & $16(5.1)$ & $84(6)$ & $0.87(0.55-1.38)$ & 0.5642 \\
\hline \multicolumn{5}{|l|}{ Parity status, n (\%) } \\
\hline Nulliparous & $45(14.5)$ & $198(14.1)$ & 1 & \\
\hline Parous & $266(85.5)$ & $1201(85.9)$ & $0.98(0.73-1.30)$ & 0.8848 \\
\hline \multicolumn{5}{|l|}{ Breast feeding history } \\
\hline No & $82(26.4)$ & $378(27)$ & 1 & \\
\hline Yes & $229(73.6)$ & $1021(73)$ & $1.02(0.81-1.29)$ & 0.8146 \\
\hline \multicolumn{5}{|l|}{ Menopausal status, n (\%) } \\
\hline Postmenopausal & $130(41.8 \%)$ & $794(56.8 \%)$ & 1 & \\
\hline Premenopausal & $181(58.2 \%)$ & $605(43.2 \%)$ & $1.63(1.33-2.00)$ & $<0.0001$ \\
\hline \multicolumn{5}{|l|}{ Hormone consumption, n (\%) } \\
\hline No & $222(71.4)$ & $1001(71.6)$ & 1 & \\
\hline Yes & $89(28.6)$ & $398(28.4)$ & $1.00(0.80-1.25)$ & 0.9525 \\
\hline \multicolumn{5}{|l|}{ Diabetes status } \\
\hline No & $268(86.2)$ & $1189(85)$ & 1 & \\
\hline Yes & $43(13.8)$ & $210(15)$ & $0.92(0.68-1.23)$ & 0.5970 \\
\hline \multicolumn{5}{|l|}{ Smoking history } \\
\hline No & $290(93.2)$ & $1308(93.5)$ & 1 & \\
\hline Yes & $21(6.8)$ & $91(6.5)$ & $1.03(0.69-1.54)$ & 0.8727 \\
\hline
\end{tabular}




\begin{tabular}{|lllll|} 
No & $162(52.1)$ & $724(51.7)$ & 1 & \\
Yes & $149(47.9)$ & $675(48.3)$ & $0.98(0.80-1.20)$ & 0.9139 \\
& & & & \\
\hline Type of surgery & & & & \\
BCS $^{\text {MRM }}$ & $195(62.7)$ & $868(62)$ & 1 & 0.8291 \\
& $116(37.3)$ & $531(38)$ & $0.98(0.79-1.20)$ & \\
\hline
\end{tabular}

${ }^{a}$ FBC: Familial breast cancer, ${ }^{b} S B C$ : Sporadic breast cancer, ${ }^{c} \mathrm{RR}$ : relative risk, ${ }^{\mathrm{d}} \mathrm{Cl}$ : confidence interval, $\mathrm{BCS}^{\mathrm{e}}$ : breast conserving surgery, $\mathrm{MRM}^{\mathrm{f}}$ : modified radical mastectomy

Table3. Association between family history and pathological characteristics of breast cancer patients in cancer research center 


\begin{tabular}{|c|c|c|c|c|}
\hline VARIABLES & $\begin{array}{l}\text { Group A } \\
\text { FBC }^{a}(n=311)\end{array}$ & $\begin{array}{l}\text { Group B } \\
\operatorname{SBC}^{b}(n=1399)\end{array}$ & $\operatorname{RR}^{c}\left(95 \% \mathrm{Cl}^{d}\right)$ & $p$ value \\
\hline \multicolumn{5}{|l|}{ Histological type n (\%) } \\
\hline Insitu carcinoma & $0(0 \%)$ & $9(0.6 \%)$ & 1 & \\
\hline Invasive ductal carcinoma & $290(93.3 \%)$ & $1273(90.9 \%)$ & $3.71(0.24-55.47)$ & 0.3414 \\
\hline \multirow{2}{*}{$\begin{array}{l}\text { Invasive lobular } \\
\text { carcinoma }\end{array}$} & $15(4.8 \%)$ & $60(4.4 \%)$ & $4.07(0.26-63.04)$ & 0.3142 \\
\hline & $6(1.9 \%)$ & $57(4.1 \%)$ & $2.03(0.12-33.34)$ & 0.6196 \\
\hline \multicolumn{5}{|l|}{ Tumor Stage, n (\%) } \\
\hline I & $51(16.4)$ & $311(22.2)$ & 1 & \\
\hline$\|$ & $161(51.8)$ & $650(46.5)$ & $1.40(1.05-1.88)$ & 0.0203 \\
\hline III & $95(30.5)$ & $371(26.5)$ & $1.44(1.06-1.97)$ & 0.0200 \\
\hline IV & $4(1.3)$ & $67(4.8)$ & $0.40(0.15-1.07)$ & 0.0683 \\
\hline \multicolumn{5}{|l|}{ Tumor size n (\%) } \\
\hline $\mathrm{T} 1$ & $59(19.1 \%)$ & $286(20.4 \%)$ & 1 & \\
\hline $\mathrm{T} 2$ & $148(47.6 \%)$ & $659(47.2 \%)$ & $1.07(0.81-1.41)$ & 0.6173 \\
\hline $\mathrm{T} 3$ & $48(15.2 \%)$ & $204(14.6 \%)$ & $1.11(0.79-1.57)$ & 0.5399 \\
\hline $\mathrm{T} 4$ & $56(18.1 \%)$ & $250(17.8 \%)$ & $1.07(0.77-1.49)$ & 0.6888 \\
\hline \multicolumn{5}{|l|}{ Nodal status, n (\%) } \\
\hline \multirow{2}{*}{$\begin{array}{l}\text { Node-negative } \\
\text { Node-positive }\end{array}$} & $86(27.6 \%)$ & $555(39.7 \%)$ & 1 & \multirow[b]{2}{*}{0.0001} \\
\hline & $\begin{array}{l}225 \\
(72.4 \%)\end{array}$ & $844(60.3 \%)$ & $\begin{array}{l}1.57(1.25 \\
-1.97)\end{array}$ & \\
\hline \multicolumn{5}{|l|}{ Lymphovascular invasion } \\
\hline Negative & $166(53.4)$ & $836(59.7)$ & 1 & \\
\hline Positive & $145(46.6)$ & $563(40.3)$ & $1.24(1.01-1.51)$ & 0.0386 \\
\hline \multicolumn{5}{|l|}{ P53 Status } \\
\hline Negative & $180(57.9)$ & $909(64.9)$ & 1 & \\
\hline Positive & $131(42.1)$ & $490(35.1)$ & $1.27(1.04-1.56)$ & 0.0182 \\
\hline
\end{tabular}


Tumor grade, $\mathrm{n}(\%)$

Well diff

Moderately diff

Poorly diff

\begin{tabular}{|c|c|c|}
\hline $21(6.7 \%)$ & 168 & 1 \\
\hline $\begin{array}{l}154 \\
(49.5 \%)\end{array}$ & 857 (39.8\%) & $\begin{array}{l}1.37(0.89 \\
-2.10)\end{array}$ \\
\hline $\begin{array}{l}136 \\
(43.8 \%)\end{array}$ & 374 (26.7\%) & $\begin{array}{l}2.40(1.56 \\
-3.68)\end{array}$ \\
\hline
\end{tabular}

0.1492

0.1492

0.0001

Receptor status, n (\%)

ER positive

ER negative
184

(59.0\%)

127

$(41.0 \%)$

$$
\begin{array}{ll}
857(61.3 \%) & 1 \\
542(38.7 \%) & \begin{array}{l}
1.07(0.87 \\
-1.31)
\end{array}
\end{array}
$$

0.0003

1

$$
1.44(1.18-1.77) \quad 0.0798
$$

HER2 positive

HER2 negative
$166(53.3 \%)$

$809(57.8 \%)$

$590(42.2 \%)$

377 (26.9)

99 (31.9)

$212(68.1)$
1022 (73.1) 1

$0.82(0.66-1.02)$

${ }^{a} \mathrm{FBC}$ : Familial breast cancer, ${ }^{\mathrm{b}} \mathrm{SBC}$ : Sporadic breast cancer, ${ }^{\mathrm{C} R R}$ : relative risk, ${ }^{\mathrm{d}} \mathrm{Cl}$ : confidence interval

Table 4. Comparison of local recurrence, distant recurrence over 5 years, the five-year disease-free survival (DFS) rate and the five-year overall survival rate (OS) between Group A and Group B Breast Cancer. 


\begin{tabular}{|c|c|c|c|c|}
\hline Group & $\begin{array}{l}\text { Included } \\
\text { patients, } \mathrm{n}\end{array}$ & $\begin{array}{l}\text { 5-years local recurrence-free survival, n } \\
\text { (\%) }\end{array}$ & $\mathrm{RR}^{\mathrm{c}}\left(95 \% \mathrm{Cl}^{\mathrm{d}}\right)$ & $\begin{array}{l}\text { P- } \\
\text { value }\end{array}$ \\
\hline Group A & 311 & $301(96.8)$ & 1 & 0.8022 \\
\hline \multicolumn{5}{|l|}{$\mathrm{FBC}^{\mathrm{a}}$} \\
\hline \multirow{2}{*}{$\begin{array}{l}\text { Group B } \\
\text { SBC }^{b}\end{array}$} & 1399 & $1350(96.5)$ & $\begin{array}{l}0.91(0.47- \\
1.89)\end{array}$ & \\
\hline & & \multicolumn{3}{|l|}{$\begin{array}{l}5 \text {-years distant recurrence-free } \\
\text { survival, } n(\%)\end{array}$} \\
\hline Group A & 311 & $262(84.2)$ & 1 & 0.0031 \\
\hline \multicolumn{5}{|l|}{ FBC } \\
\hline \multirow[t]{2}{*}{$\begin{array}{l}\text { Group B } \\
\text { SBC }\end{array}$} & 1399 & 1259 (89.9) & $\begin{array}{l}1.57(1.16 \\
-2.12)\end{array}$ & \\
\hline & & \multicolumn{3}{|l|}{ 5-year DFS ${ }^{e}$ Rate, n (\%) } \\
\hline Group A & 311 & $252(81)$ & 1 & \\
\hline FBC & & & & 0.0121 \\
\hline \multirow[t]{2}{*}{$\begin{array}{l}\text { Group B } \\
\text { SBC }\end{array}$} & 1399 & $1210(86.5)$ & $\begin{array}{l}1.40(1.07- \\
1.83)\end{array}$ & \\
\hline & & 5-year OS ${ }^{f}$ Rate, $n(\%)$ & & \\
\hline Group A & 311 & $221(71.1)$ & 1 & \\
\hline FBC & & & & 0.0401 \\
\hline $\begin{array}{l}\text { Group B } \\
\text { SBC }\end{array}$ & 1399 & $1070(76.5)$ & $\begin{array}{l}1.23(1.01- \\
1.50)\end{array}$ & \\
\hline
\end{tabular}

${ }^{a}$ FBC: Familial breast cancer, ${ }^{b} S B C$ : Sporadic breast cancer, ${ }^{c} R R$ : relative risk, ${ }^{d} \mathrm{Cl}$ : confidence interval, eDFS: Disease-free survival, ${ }^{\mathrm{f} O S}$ : Overall survival 